\title{
Slide cricotracheoplasty in an infant
}

Emmanuel Le Bret, MD, PhD, ${ }^{a}$ Eréa Noel Garabédian, MD, ${ }^{\mathrm{b}}$ Natacha Teissier, MD, ${ }^{\mathrm{b}}$ Emre Belli, MD, Noureddine Gharbi, MD, ${ }^{a}$ Jacqueline Bruniaux, MD, ${ }^{a}$ Régine Roussin, MD, ${ }^{a}$ Anne Sigal-Cinqualbre, MD, ${ }^{\mathrm{c}}$ and Alain Serraf, MD, PhD, ${ }^{a}$ Le Plessis Robinson and Paris, France

See related brief communication on page 181 .

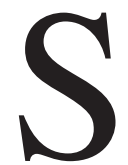

lide tracheoplasty was first described in 1989 by Tsang and colleagues $^{1}$ and has now become the gold standard to treat long-segment tracheal stenosis. This technique presents several advantages: no graft material is required, it allows satisfactory enlargement of the trachea, and it does not hinder the functional growth of the trachea. ${ }^{2,3}$ Recently, our team has reported the association of tracheal resection and slide tracheoplasty to manage an infant presenting with tracheal hypoplasia associated to a partial critical stenosis. ${ }^{4}$ However, surgical management of a tracheal hypoplasia extending up to the cricoid is still quite challenging. ${ }^{5}$

We therefore describe a variant of the slide tracheoplasty that allowed us to treat this difficult case.

\section{Clinical Summary}

A 3-month-old infant weighting $4.8 \mathrm{~kg}$ was primarily referred for critical tracheal stenosis. The child was intubated, but satisfactory ventilation was difficult despite a high peak airway pressure. Endoscopy and computed tomographic scan analysis showed complete tracheal hypoplasia starting at the cricoid level and extending to the carina (Figure 1). The carina was preserved.

Surgical technique. A transverse cervical incision combined with a median sternotomy was performed. Extensive dissection of the trachea was accomplished, with section of the suprahyoid insertions and mobilization of the main bronchi. After establishing cardiopulmonary bypass between the right atrium and the aorta, the trachea was first transversally transected at the middle portion. The distal end of the trachea was longitudinally divided along its anterior wall down to the carina. The carina was normal. The proximal end of the trachea was also longitudinally sectioned along the entire length of the posterior wall. At the level of the cricoid junction, the diameters of the trachea and the cricoid were still too small. The cricoid had a normal anatomy, but the lumen was narrowed: the internal diameter measured no more than $3 \mathrm{~mm}$.

From Service des Cardiopathies Congénitales ${ }^{\mathrm{a}}$ and Département d'imagerie Médicale, ${ }^{\mathrm{b}}$ Centre chirurgical Marie Lannelongue, Le Plessis Robinson, France, and Département d'ORL Pédiatrique, Hôpital d'enfants Armand Trousseau, ${ }^{\mathrm{c}}$ Université Paris VI, Paris, France.

Received for publication Dec 2, 2005; accepted for publication Jan 13, 2006.

Address for reprints: Emmanuel Le Bret, MD, PhD, Service des Cardiopathies Congénitales, Centre Chirurgical Marie Lannelongue, 133 avenue de la Résistance, 92350 Le Plessis Robinson, France (E-mail: e.lebret@ccml.fr).

J Thorac Cardiovasc Surg 2006;132:179-80

$0022-5223 / \$ 32.00$

Copyright () 2006 by The American Association for Thoracic Surgery doi:10.1016/j.jtcvs.2006.01.009
The posterior wall of the cricoid was split medially and resected. The right-angled corners of the tracheal wall were trimmed to allow fine adaptation to the larynx. The anastomosis was performed with interrupted 5-0 polydioxanone sutures (Ethicon, Inc). Sutures were initiated proximally between the superior tongue of

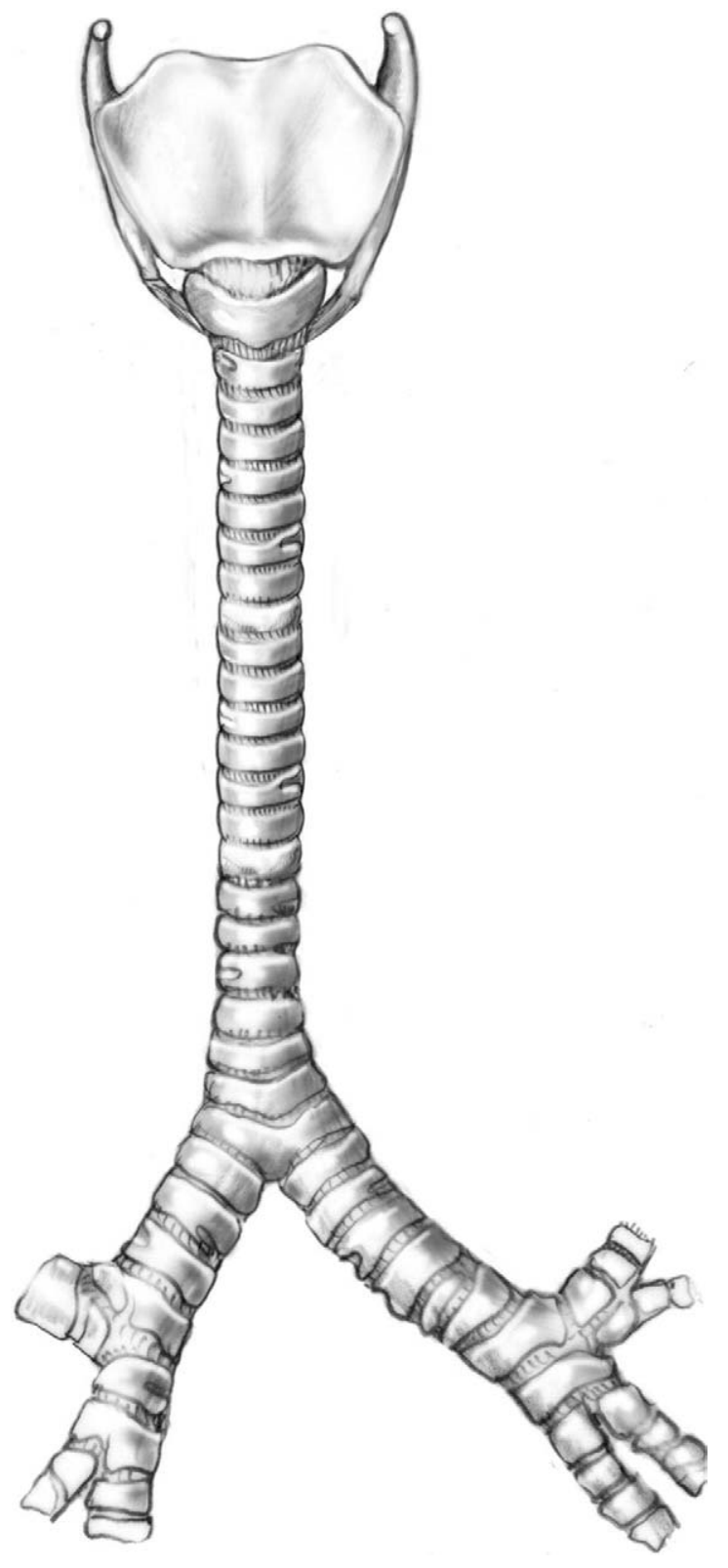

Figure 1. The hypoplasia started at the cricoid level and extended to the carina. 


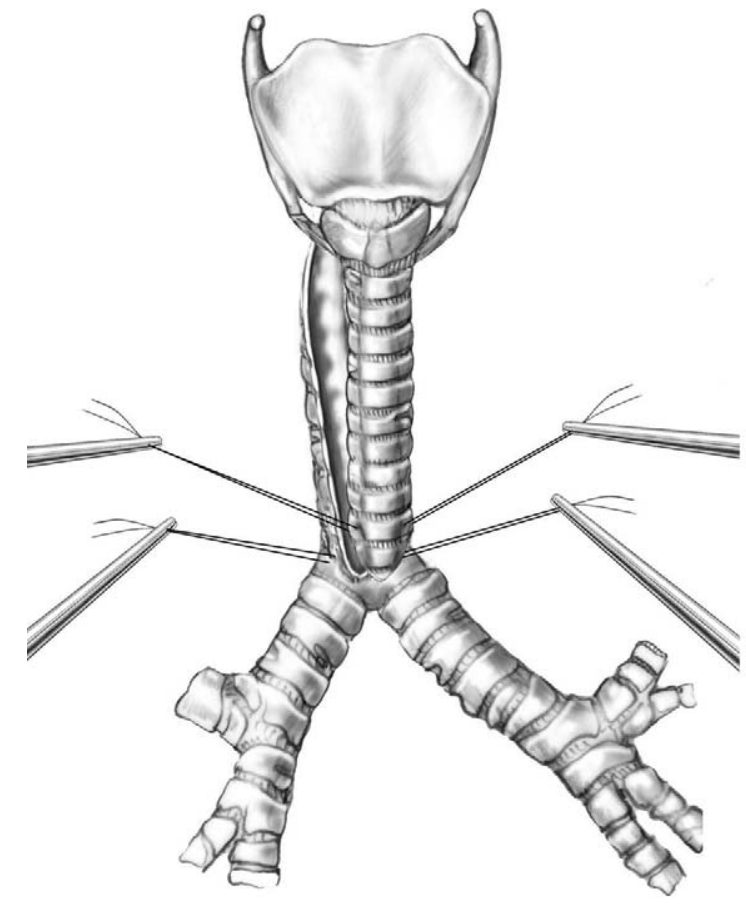

A

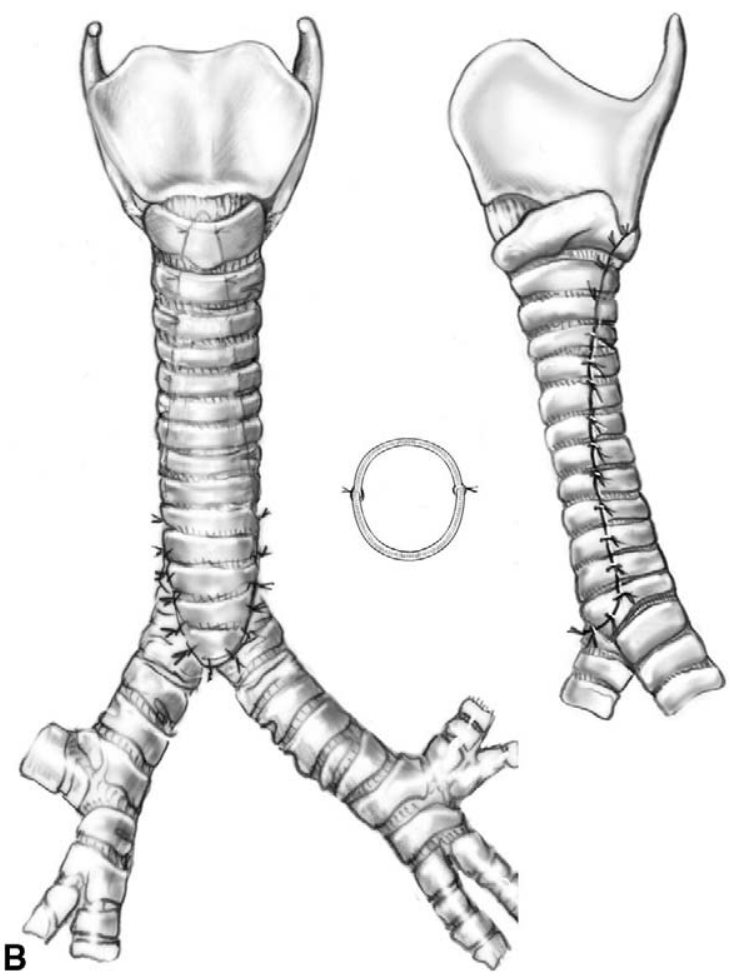

Figure 2. The slide tracheoplasty was extended to the posterior part of the cricoid.

the trachea, the inferior part of the larynx, and the open cricoid cartilage (Figure 2). The final sutures were placed at the distal end of the tongue of the anterior wall of the trachea, which was sutured down to a point at the anterior part of the carina. The endotracheal tube was replaced, ventilation was re-established, and the patient was weaned from cardiopulmonary bypass.

Follow-up. The patient was extubated on the fifth postoperative day under bronchoscopic control. He had to be reintubated from J12 to $\mathrm{J} 15$ for pulmonary congestion and unilateral vocal cord paralysis. A resection of the aryepiglottic fold and bronchoscopic granuloma excision were necessary before extubation. At 12 months, the child was doing perfectly well, and bronchoscopic examination showed a nice tracheal and cricoid repair without granulomatous tissue and a left vocal cord paralysis.

\section{Discussion}

A case of cricoid stenosis associated to partial tracheal stenosis was reported in 2002 by Han and coworkers. ${ }^{5}$ In his case the stenotic segment was found to extend from the cricoid cartilage to the upper fifth tracheal cartilage, with maximum stenosis at the cricoid level. The technique used to treat this association consisted of splitting the anterior surface of the cricoid up to the cricothyroid membrane, splitting the anterior wall of the upper trachea, and then sliding the lower segment anterior to the cricoid. In this technique a portion of the anterior cricoid arc was resected.

In our case of extended tracheal hypoplasia associated to cricoid stenosis, we preferred to slide the lower part of the trachea posterior to the cricoid and to open and resect partially the posterior part of the cricoid. We think this technique allows a better vascularization by avoiding a large posterior dissection of the lower trachea. However, the dissection of the posterior part of the cricoid is more dangerous for the recurrent nerves.

\section{Conclusion}

Extended slide tracheoplasties achieved successful tracheal reconstruction, even when the cricoid was involved in the hypoplasia. Use of the patient's own tracheal tissues and avoidance of foreign materials should allow good cricotracheal growth in the same way that slide tracheoplasty allows good tracheal growth.

\section{References}

1. Tsang V, Murday A, Gilbe C, Goldstraw P. Slide tracheoplasty for congenital funnel shaped tracheal stenosis. Ann Thorac Surg. 1989;48: $632-5$.

2. Macchiarini P, Dulmet E, de Montpreville V, Mazmanian GM, Chapelier A, Dartevelle P. Tracheal growth after slide tracheoplasty. J Thorac Cardiovasc Surg. 1997;113:558-66.

3. Grillo HC, Wright CD, Vlahakes GJ, McGillivray TE. Management of congenital tracheal stenosis by means of slide tracheoplasty or resection and reconstruction, with long term follow-up of growth after slide tracheoplasty. J Thorac Cardiovasc Surg. 2002;123:145-52.

4. Garabedian EN, Le Bret E, Corre A, Roger G, Pineau E, Bourel P. Tracheal resection associated with slide tracheoplasty for long segment congenital tracheal stenosis involving the carina. J Thorac Cardiovasc Surg. 2001;121:393-5.

5. Han SJ, Kim YH, Kim MJ, Lee KY, Han A, Hwang EH. Slide cricotracheoplasty: a novel surgical technique for congenital cricotracheal stenosis. J Pediatr Surg. 2002;37:E36. 